\title{
ROLE OF INFORMATION AND COMMUNICATION TECHNOLOGY IN AGRICULTURE DEVELOPMENT: A STUDY OF NABARANGPUR DISTRICT
}

\author{
Neelesh Pandey \\ Ph.D Scholar, Department of Journalism and Mass Communication \\ Central University of Orissa, Koraput, India.
}

\begin{abstract}
Today India is passing through the phase of communication revolution, which has brought about a significant growth of media in mass communication. It has become an important part of development initiatives in health, nutrition, agriculture, family planning, education, community economy and world empowerment. The present study aims to study the agriculture development with the emergence of the new communication technology. The study is being undertaken to know how agriculture development is possible through an effective communication tools that is ICT (Information and Communication Technology).
\end{abstract}

ICT includes communication device or application, encompassing cellular phones, computer, internet and network hardware and software, satellite systems and so on, as well as the various services and applications associated with them, such as videoconferencing and distance learning. ICTs are often used in areas like education, agriculture, health care, or libraries. Therefore, the present investigation was undertaken to study about how the use of ICT helps in agricultural development in rural areas. For the present study for knowing the use of ICT among the farmers, Nabarangpur district of Odisha is being chosen. As a sample the Raighar Block of the district was chosen to know the use of technology among the farmers.

The sample of the study is 170 comprising of locals farmers of Raighar, seeds company's agents and ICT experts, selected with a simple random sampling methods, randomly with an age group from 20 years to 55 years. The data were collected through a structured with simultaneous observation of responses from the sample. Data were analysed with different statistical measures through percentage and frequency of the data.

KEYWORDS: ICT, Agriculture, Raighar, Farmers, ICT experts.

\section{Introduction}

Information and Communication Technology (ICT) has been considered as a tool that can be used to achieve development goals in developing countries. These technologies may help to fight against illiteracy, disease, unemployment, poverty, agriculture and other development problems. Agriculture plays a vital role in the society and the economy of the country. Nowadays, more and more new advanced technologies are used for agricultural development, such as satellites, the Internet, mobile phone and social media. The use of the technologies and divides in both developed and developing nations can be used to improve agricultural information and farming methods with transformational development (Lu, 2001). In India around $70 \%$ of population earns its livelihood from agriculture. According to census 2011, 68.9 percent (83.3 Crore) population is still rural. The agriculture sectors more than half the output of the Indian economy. (Kurukhetra, June 2015). 
Agriculture needs continuous diffusion of new technology to meet global food security, poverty reduction and environment sustainability. According SECC data (2011), released on 2015, in India total households is 24.39 crore, out of 17.91 crore lived in rural area, among them 10.69 core called deprived households (Kurukshetra, September 2015). The SECC data indicates that 31.26 percent of rural households are belonging under poverty. The life of main earner is highly unsecure and uncertain income. Due to globalization, urbanization and demand of high value product global scenario has been change in the context of agriculture. Farming is very difficult for people though are lives under poverty line. To mitigate the global needs and reforms agriculture production, Green Revolution took placed during the mid of 1960s. The major objectives of green revolution were expansion in area under cultivation, usage of chemical fertilizers, pesticides and new technologies to increase the output. In India conducted under the eminent scientist M.S.Swaminathan and team of Scientist of ICAR (Indian Council for Agriculture Research). Green revolution, which increased the output of cereals- mainly rice and wheat and other core cereals like maize to a certain extent, mainly in Punjab, Haryana, and western Uttar Pradesh. At the initial stage, green revolution was initiated with the spread of new technology to better endowed and irrigated area. Later many revolutions occurred in India to increased various other types of production such as white revolution (milk production), blue revolution ( fish production), yellow revolution (oil seeds), round revolution (potato production) evergreen (productivity without loss), silver fibre (cotton production), silver revolution (poultry production), red revolution (meat and buffalo), golden (overall horticulture) etc. instead of these types of revolution many farmers in India following traditional way of cultivation. Every year plenty of farmers are facing huge loss during cultivation. Agriculture production continuously decline during the last few decades. Hence agriculture development need through provide innovative knowledge and information to door step of farmers.

Development education, it combines various methodologies of education to promoting knowledge, so that agriculture sector needs development education to revive productivity through agriculture. ICT (Information communication technology) help to provide knowledge to the door step of farmers. It provides information related to weather/climate information, fertilizers consumption, online land registration, pest management and price output in the markets etc. Every level of government offices are connected with a network, to provide information to the farmers. Agriculture expert, VAW (Village Agriculture Workers), Krisak Sathi, development officers and stake holder are teaching farmers, to adapt new methods of agriculture. In India teledensity has rapidly increased, in rural area teledensity is increased twice as per 2015 government report (Kurukshetra, February 2016). Rural farmers access information regarding agriculture through Short Message Service (SMS), Voice over call on their mobile phone. The Central government collaborating with the state government has been introduced in various ICT Centres equipped with PCs, telephone, internet, broadband connection and with development officer e.g. e-choupal, cyber dhaba, IFFCO-ISRO GIS project, Gyandoot project, AMARKET,VISTANET etc. Knowledge based information provided through various web and mobile based web portal, farmer's web portal (www.farmer.gov.in), mkisan portal (www.mkisan.gov.in), Kisan Call Centres. These portal are facilitating knowledge based information and advisory through subject experts. Department of Agriculture \& Cooperation has developed more than 80 portals, websites and mobile based applications, with the collaboration with National Informatics Centre. The important portals are, SEEDNET, DACNET, RKVY, ATMA, NHM (National Horticulture Mission), INTRADAC, NFSM (National Food Security Mission) and APY (Acreage, Productivity and Yields).

Maximum percentage of inhabitant make livelihood through agriculture. This research has given importance to know about the various projects of ICTs in agriculture development. Special ICTs projects in Odisha and how the government and private organization design programmers to reach the rural farmers.

\section{ICT and Agricultural development}

ICTs in agriculture have the potential to facilitate greater access to information that drive or support knowledge sharing. ICTs essentially facilitate the creation, management, storage, retrieval, and dissemination of any relevant data, knowledge, and information that may have been already been processed and adapted (Bachelor 2002; Chapman and Slay maker 2002; Rao 2007; Heeks 2002). As the study is about the divergence of ICTs and its application must makes for development particularly in the field of 
agriculture. ICT in agriculture is an emerging field focusing on the enhancement of agriculture and rural development in India. ICT can provide with accurate information necessary for the farmers which facilitates better agriculture output.

Through the public private partnership, private initiatives and government programmes are made for agriculture development. But in Indian still in growing stage and evolving as an emerging trend the benefit of ICT is yet to reach all the farmers. Perhaps technological innovation many farmers, especially who are original and share cropper are not getting proper information and service due to poor economic condition and social constraints. Other factors are illiteracy, language barriers and unwillingness to adopt the new technology.

The way in which ICT projects access, assess, apply, and deliver content may increase the likelihood of ICT use by farmers and thus may become an important factor in a project's success. To address the information needs of farmers, relevant content is a key component of ICT projects. The extent to which content is customized and localized to a farmer's condition influences its relevance. Local content has been defined as content that is intended for a specific local audience, as defined by geographic location, culture, or language or as content that is socially, culturally, economically, and politically relevant to a given society. Thus, local content is the expression of a community's knowledge. Local content includes external or global content that has been transformed, adapted, and assimilated into a knowledge base. Yet ICT projects may not always be relevant to local context and needs, because of a disconnection between the project and its end users (Ballantyne 2002). The benefit of ICTs is yet to reach all the farmers, especially those who are marginal or sharecropper and living in remote part of the country are not getting this service or its better to say they are not availing this due to poor economic conditions, communication barrier and social constraint. Other factors are illiteracy, language barrier, poverty, unwillingness to adopt the new technologies and shortage of government official in agriculture department.

\section{Scope and Significance of the study}

Indian government emphasises on "Digital India" programme. This scheme aim to empower citizens with e-access to government services and livelihood related services. By the end of 2019 the Digital India programme envisages that 2,50,000 Indian villages will enjoy broadband connectivity and universal phone connectivity. Government of India began to adopted information concept in route to development during 1980s during the Prime Minister Rajiv Gandhi. The study has focused the use of ICTs to access agriculture information in the part of Raighar. The study has focused how the development officers and stake holders use ICTs as access and utilisation tools are the focus of the study. The study focuses on use of ICTs by information providers and how they diffuse information to access utilisation of agriculture the rural farmers of Raighar and also how farmers of Raighar in rural remote area access information and utilise the benefit of ICTs in agriculture development.

\section{Literature Review}

Among the various researches conducted on subject related to this work, the works are very much related to communication ICT and role of ICT in rural development in the field like health sanitation, agriculture, education, and economy they are:

Gupta $(2006)^{\mathrm{i}}$, point out the role of information and communication in social and economic development of individual, society and nation this book examine the exiting field of development communication and illustrates how this field of the study is composed and telecommunication are consider central to rural and nation development and also discussed the biases of the development, communication technology for gender; folk media and development communication.

Sharma $(2004)^{\mathrm{ii}}$, in his work bring out communication age centre on the evaluation of electric information technology (IT) help in processing of information had dominated the $21^{\text {st }}$ century and will continue to dominate in the future too. The information and technology has been a technician synthesis of computer and communication technologies it impact in lives. The service of mankind with the influence on all aspect 
of society it's helping from last few decades. It is continuously improving the lives of people growth of campaign and changing the society by improving communication and its media.

Mohanty and Bohra (2006) ${ }^{\mathrm{iii}}$, highlights, the role of ICT all across the globe with the emergence of various technologies ICT played a significant role which has not only made access across the globe easier but has facilitated integration of thought, process synergies in working methods and place, participation and democratic function approach in learning and the enhancing organisation transparency increasing awareness to and application of e-governance has opened newer vistas of management system and facilitation strategies.

To discuss about development communication in rural sectors, Dasgupta, Choudhary \& Mukhopadhyay $(2007)^{\text {iv }}$ point out the concept with reference to media for agriculture development. While discussing communication models for technology transfer and research and development, they discuss how to generate and transfer of adoption technologies needs for reconstructing the models of agriculture communication. Advantage of communication technologies help in rural development and advantage of information technology in agriculture development and impact broadcasting and tuning for farming.

In his work Bhatnagar and Schware $(2006)^{v}$, emphasize the successful use of information and communication technologies (ICT) in rural development. It begins with an introductory chapter which traces the history of the use of ICT in rural India. It examines some of the problems that have afflicted the implementations rural development programmes and show ICT application could help overcome them in future.

Narula (2011) $)^{\mathrm{vi}}$, discuss about the Dynamic of development and dysfunction of development. She also cited how these two aspects are facilitated and impeded by Development Communication models operating in specific society at a particular point of time is presented development communication challenges, Technological challenge; Reach \& strategies for development.

Melkote \& Steeves (2001) ${ }^{\mathrm{vii}}$ basically highlight the challenge for communication research in developing countries in the design of strategies that bear in mind colonial past and semi-feudal, semi-capitalist world. They present to focus on how to transcend the negative aspect of these realties. Necessity of new techniques of communication for grass root level development and how information and communication technologies work for rural development and communication strategies for empowerment.

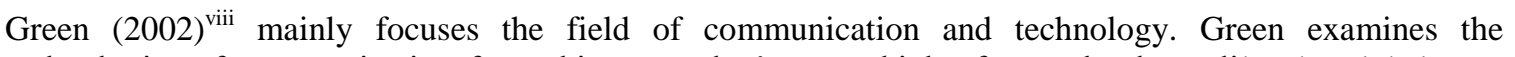
technologies of communication from things we don't even think of as technology, like the alphabet or electricity. Though to the rapidly developing world of cyber space she argues that technology is never natural rather it is closely linked to culture, society and government Green looks at what drives technological change, showing that the adoption of technologies culture coexist and interact, industrial culture and now techno-culture, while other are left out or even damage.

Singhal \& Rogers $(2011)^{\mathrm{ix}}$ assert that, new information communication change the pace of human interaction across the world. They coined the world as "Global Village" where entire world connected with each others. He mention that, in India a long way to achieving Information society, but a huge numbers of workers employed in information sectors to provide information from the ground level. Information plays a crucial role in the development process. How the new technologies and its various applications i.e. radio, $\mathrm{TV}$, cable, telecommunication, computers, and the internet are rapidly leading India towards becoming an information society. They describe the concepts "Informatisation" strategies it is the process through which communication technologies are used as a means of furthering socio-economic development. They mention various Indian communication revolutions, including proliferation of telephone, internet and software for growth of entrepreneurship, venture capital, and supportive government policies and networking between Indian entrepreneur in Silicon Valley and their Indian Based counter parts.

Hanson \& Narula $(2012)^{\mathrm{x}}$ states that, a true product of the information society in itself and subject to typical problem of postal service, telephony, and international computer transfer. How to several countries 
are responding each other due to pressure from information society. They explore the Current scenario of developing countries, infrastructure development policy, social systems and models of information technologies and society. How society accepts technologies in lifestyle and social system, needs of the various society in world perspectives.

Ghosh (2006) ${ }^{\mathrm{xi}}$ emphasize the role of communication in facilitating social change and furthering the goals of developments programme which is now widely acknowledged. However what is not so well appreciated is that the application of communication technology in social development programme is a complex task, which requires a professional approach. Based on more than years of author personal experience, this book is provide an understanding of the practical issues that arise in the planning and implementation of communication programme to bring about behaviour change in the Indian context. This book provide a historical background to the evolving nature of the application of communication technology in development case study of innovative application of communication technologies both in India and abroad are describe to assist a holistic understand of evaluation of the role of development communication.

Koshore and Gupta ${ }^{\mathrm{xi}}$, reports the availability, use and information seeking behaviour of a farming community with special reference to Information and Communication Technologies (ICTs). It fills a research gap by examining what people do with a medium when they have access to it, rather than looking at barriers surrounding the use of ICT and digital divide issues arising due to differential access and capabilities. The study conducted in a state in North India, and provides insights into intentions and factors surrounding the use of various media by farmers. It highlights the socio-cultural context within which information seeking and use occurs in rural India.

Kauffman and Kumar (2008) ${ }^{\text {xiii }}$ in their work described a new approach to measuring the macro level impacts of ICTs across a range of development areas. The indirect effect to one area on others is taken into consideration by a simultaneous equation model that permits the inclusion of multiple development areas. The model is applied to data pertaining to four development areas in 64 countries: trade flows, agricultural productivity, R\&D, and quality of life. ICT readiness is found to have a positive association with trade flows and $\mathrm{R} \& \mathrm{D}$, but the impact depends on the country's development level. The strengths and limitations of this modelling approach, and the implications of the results, are assessed.

\section{Objectives}

The objectives of the study are;

- To find out the ICTs application in agriculture in Raighar block.

- To find out role of ICTs in agriculture development.

- To assess the people's awareness towards ICTs application in agriculture development.

\section{Hypothesis}

Hypothesis of the study are:

$\mathrm{H}_{1}$ - ICTs play an emphatic role in upliftment of agriculture development.

$\mathrm{H}_{2}$-ICTs applications are still unreachable in rural areas.

$\mathrm{H}_{3}$-Mobile communication enhanced the momentum in the ICTs application for agriculture development.

\section{Research Methodology}

The present study has been completed with collecting both primary as well as secondary data.

Secondary Data Collection: The secondary data has been collected through different source of materials, portals, websites and other exiting records:

a. National and state government agriculture portal.

b. Policy and act of Orissa Government.

c. Different Schemes and Projects on ICT under Government of Orissa.

d. Block agriculture reports. 
The other relevant data has been collected from various books, magazines, official records, research paper, internet, journals, news articles and other exiting sources of data.

Sample Design: To study the role of ICT in an area like Raighar in Nabarangpur district, the sample has been designed as per the feasibility of the research conducted in the stipulated time.

Population of the Study: The population of the study is 29,755 comprised of farmers agriculture labours (private agencies) though are directly linked with the agriculture.

Sample Area: Raighar block play significant role in maize production, in Orissa's agriculture. About $80 \%$ of people are directly connected with agriculture and agro based industries which provide livelihood to the inhabitants of the block. Two Grampanchayats have been selected out of 24 panchayats for data collection as per agricultural activities, one highest agriculture activities another one lowest activities. The selected area of sample from Raighar block comprises 16 different villages 8 villages from each two panchayat and sample is persons, who are big and small farmers. Hence ICT implementation is required where it's feel the lack of information. The research conducted is a descriptive research.

Sample Size: The size of the sample is 170 consists of: Farmers 160, Government officials 4, Stake holder (Private agents of seeds and fertilizer companies) 4, ICTs Experts- 02.

Sample Selection: The sample was drawn through simple random sampling methods. Through stratified random sampling methods 10 farmers have been selected from each village, there have eight revenue villages in each panchayat.

Two types of methods are selected to collect the data to conduct the research. The data has been collected in different phase as per needs from different villages of Raighar Block.

Primary Data Collection: The primary data has been collected through two methods survey and observation. Through schedule, data has been collected from the farmers of selected villages. From each village ten farmers has been taken. Selection has been made through the register of stake holders. Schedule has been prepared with both close ended and open ended questionnaire. While collecting primary data non-participatory observation a method has been followed.

Tools and Techniques: Schedule has been used as a tool of survey method.

Data analysis: Data are analyzed in qualitative and quantitative methods. Data collected from both panchayat are averagely analyzed. To know the difference a comparative analysis has also been done. To test the quantity of data SPSS software has been used. 


\section{Analysis and Interpretation:}

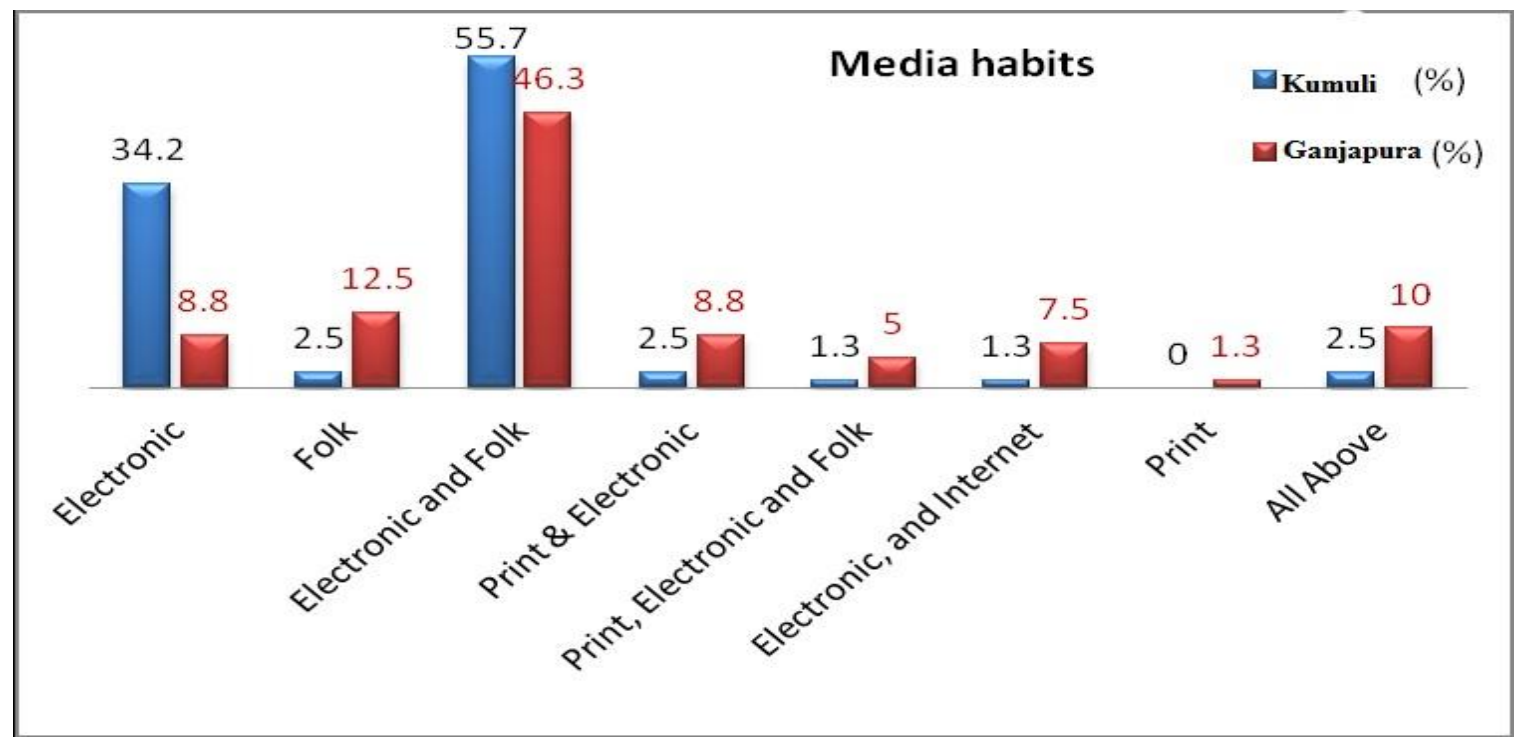

Graph No 1

Farmers are having multiple media habits don't confine with single media. An average $21 \%$ consumes only on electronic media( TV and radio), $7 \%$ only folk media, $51 \%$ both electronic and folk, $5.6 \%$ print and electronic, $3.15 \%$ print, electronic and folk, $4.4 \%$ electronic and internet, $0.65 \%$ only print and $6.25 \%$ all types of respectively. Here more than $10 \%$ of farmers have used Internet. Hence influence of electronic media (TV and Radio) and folk media is higher than other media.

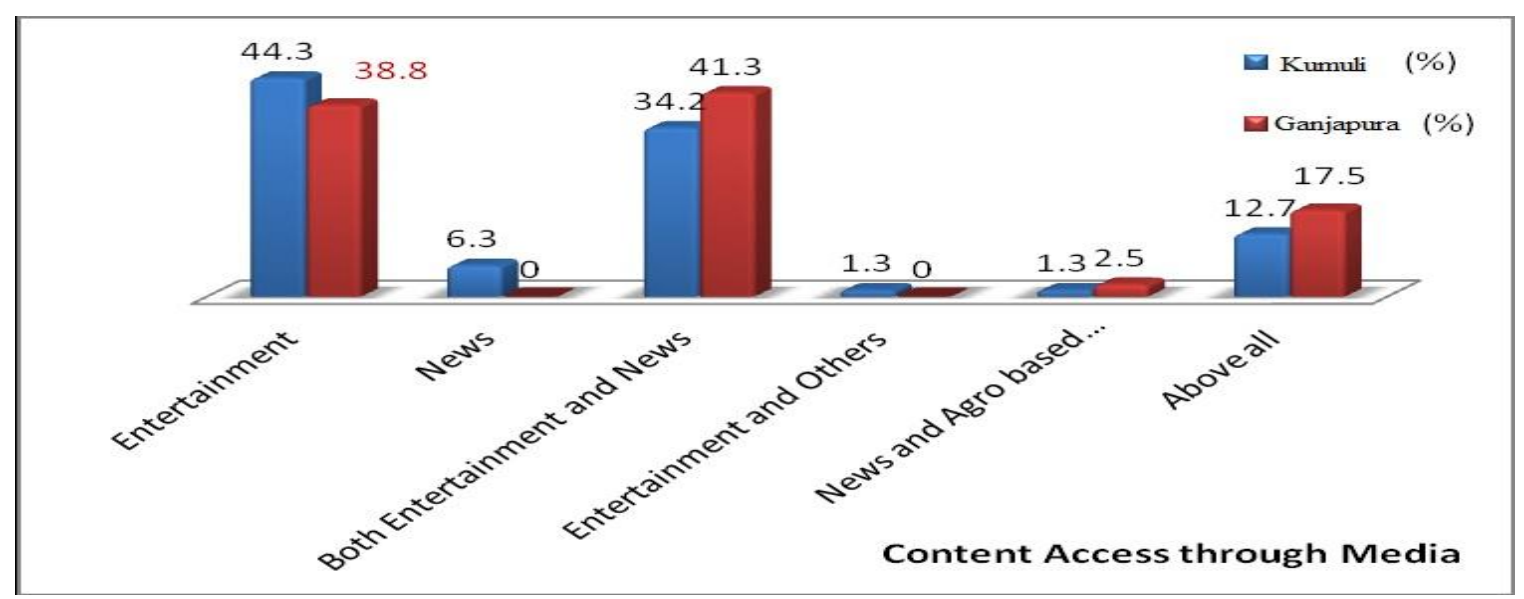

Graph No 2

Media consumption is almost equal in both sides because farmers spending their rest time on entertainment. Only spending on entertainment average percentage is $41.55 \%, 3.15 \%$ only news programme, both entertainment and news are $37.75 \%$, entertainment and others $0.65 \%$, news and agriculture related information around $2 \%$ and all types of programme are $15.1 \%$. Though are information oriented they willfully go through the agro based information and news channel. As a result, $15.1+1.9=17 \%$ of farmers are curiously searching information as per their needs through media. 


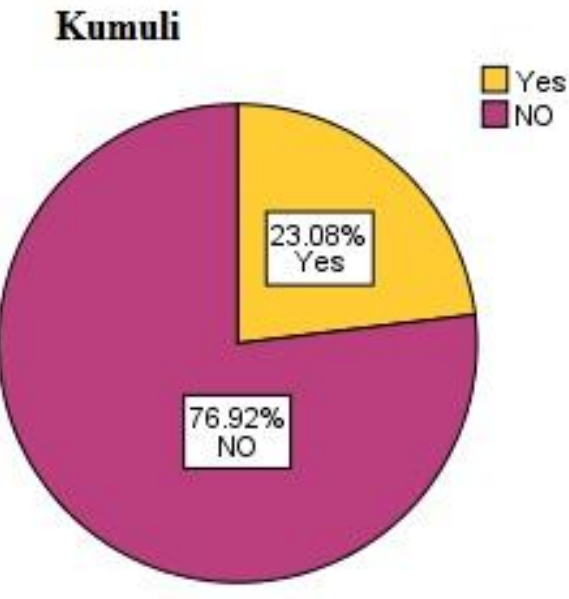

Pie Chart No 1

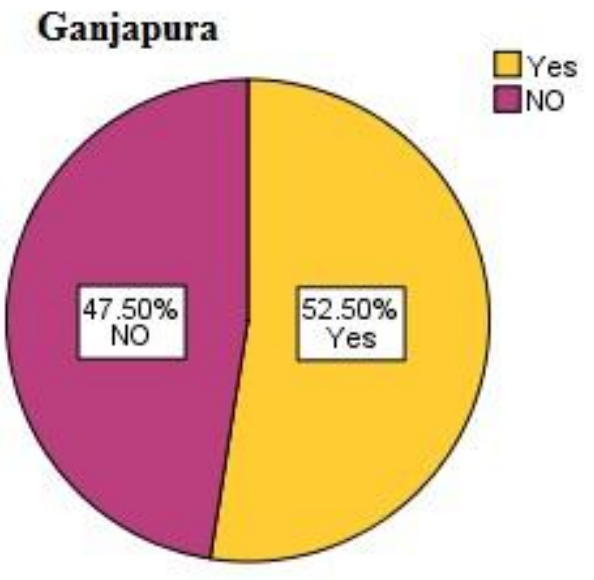

Pie Chart No 2

DD Kisan, India's one of the completely agro based channel. The channel has broadcasting only agriculture based programmes, but an average $37.79 \%$ people are known about the channel, while $62.21 \%$ farmers have no idea about its existence and importance.

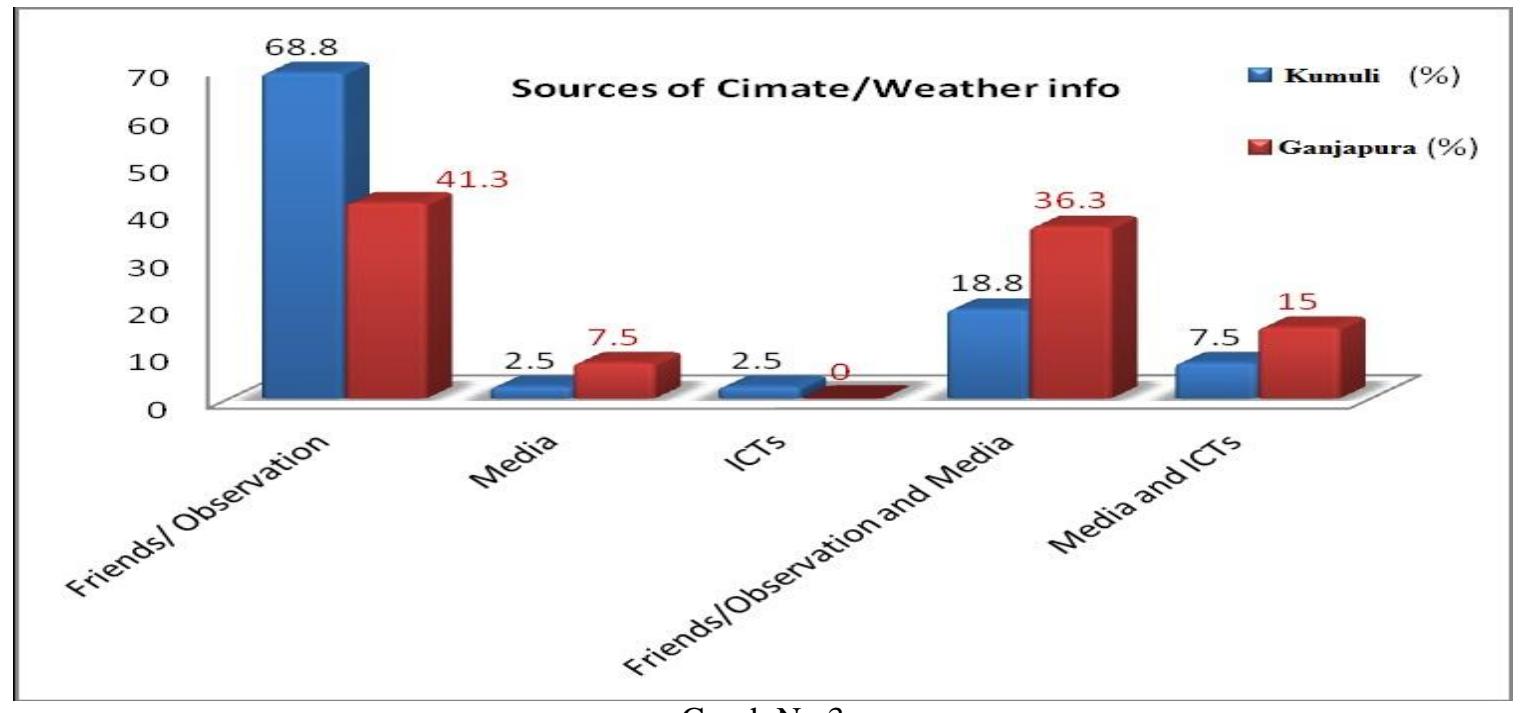

Graph No 3

Above graphs represents that, $55.5 \%$ of farmers get climate/weather related info with the observation and asking from educated friends or ICTs users. 5\% of farmers have learns through media i.e. news or weather forecast of radio or television or newspapers. Only $1.25 \%$ through the help ICTs application, $27.55 \%$ throughout various sources like friends, relatives, and family members those are ICTs users, observation and tools of media, $11.25 \%$ of them access through media and ICTs application. Hence, $1.25+11.25=12.50 \%$ an average of farmers using ICTs application for gets weather/climate info. 


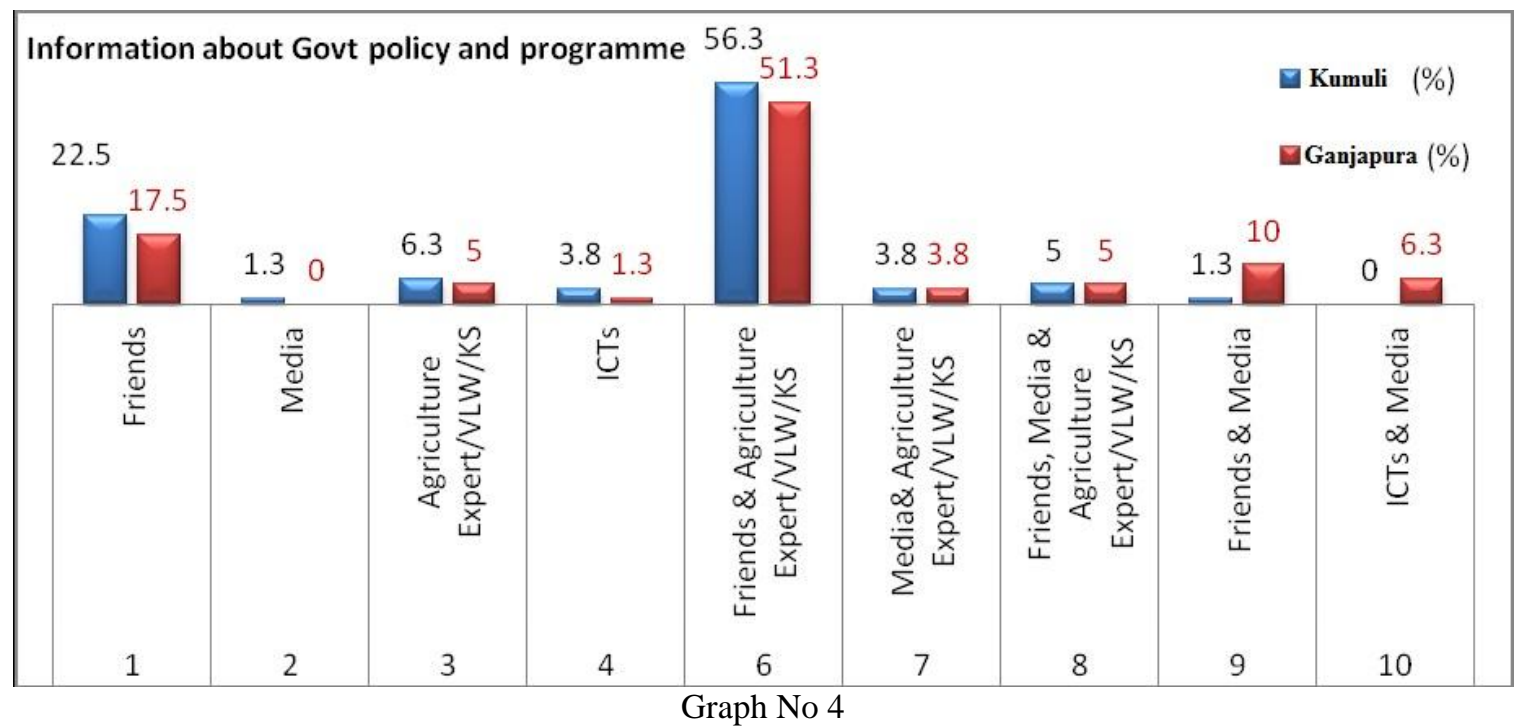

Information is transfer from one to many through inter-personal communication. An average $20 \%$ of famers get information about government policy, programme, announcement, distributions etc from friends, while $0.65 \%$ learns only through media, $5.65 \%$ from agriculture officials (Krisak Sathi, Village Level Workers and other government officials), and $2.55 \%$ directly through ICTs applications, $53.8 \%$ with the help of friends and agriculture officials, 3.8\% media and agriculture officials, 5\% through friends, media, and agriculture officials, 5.65\% with the help of friends and media, and directly through ICTs application $3.15 \%$. Therefore farmers are accessing information regarding government, policy programme and facilities with the help of ICTs applications, that percentage is $2.55+3.15=5.7 \%$.

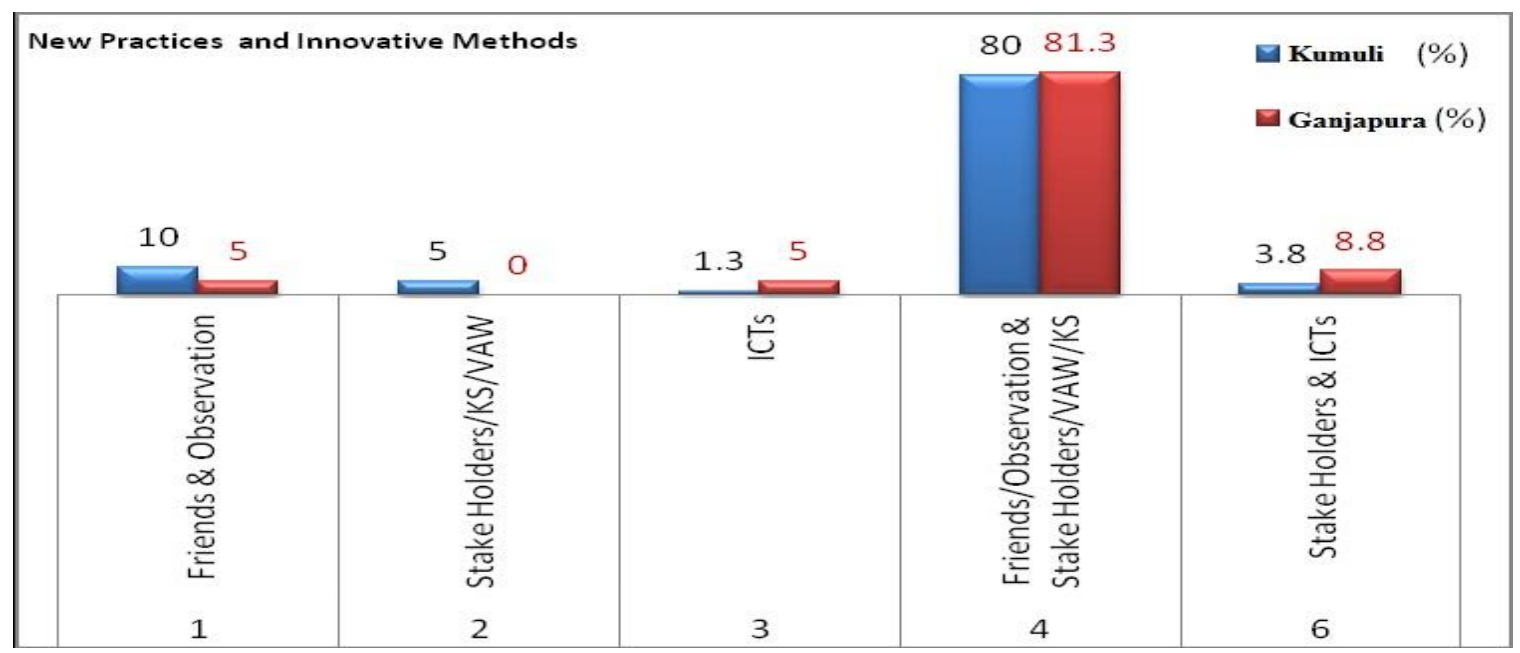

Graph No 5

Above the graphs mention about how to farmers are learns new techniques of cultivation for better production, pest management, fertilizers usage, treat different disease of crops and market price output. An average $7.5 \%$ learns, above knowledge through own experience and 22 observation from friends. $2.5 \%$ with the help of agriculture officials, $3.15 \%$ with help of ICTs application, $80.65 \%$ through the various sources like, friends, observation, government officials and stake holders, while $6.3 \%$ learns from stake holders. So that ICTs applications directly help farmers to gain new knowledge and innovative techniques and its total contribution is $3.15+6.3=9.45 \%$. 


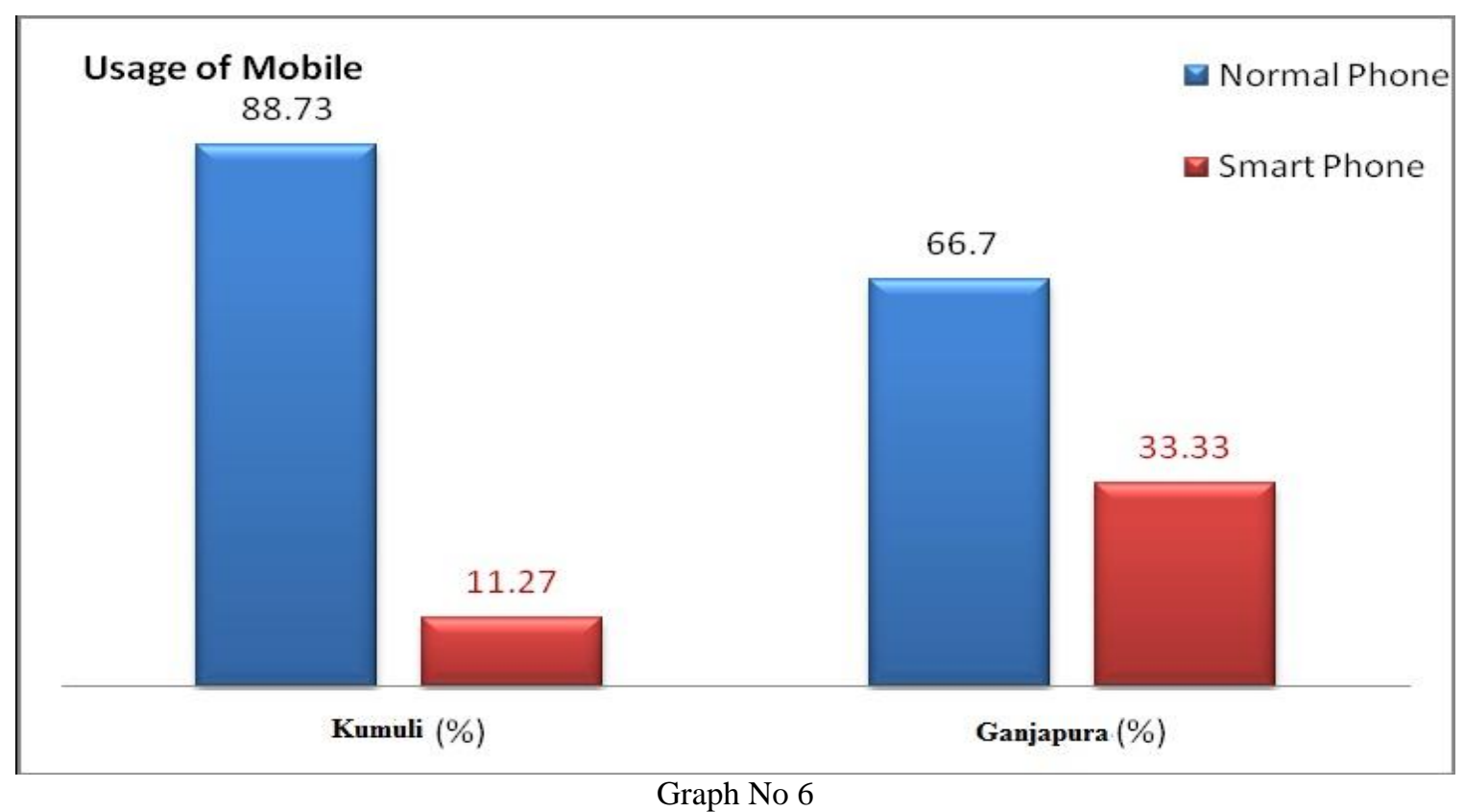

Out of total mobile users 22.3 have smart phone $77.7 \%$ have normal phone.

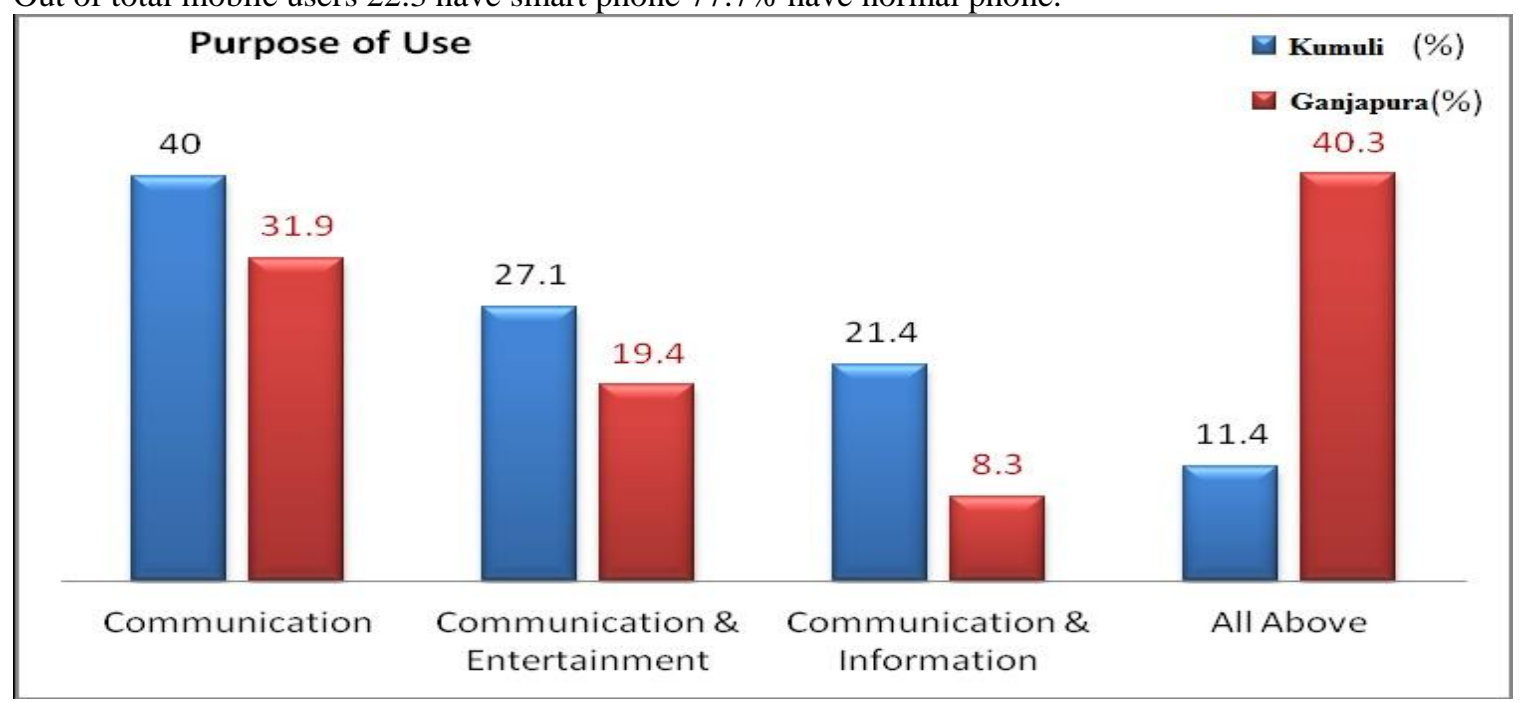

Graph No 7

Among the total percentage of mobile users, around $36 \%$ of them usage only for communication with friends and relatives, 23.29\% have using for dual purpose communication and entertainment (Play game, listen songs watching video etc), around $15 \%$ for communications and to know about agro based information (agriculture extension purpose) and 25.85 all the above types of purpose. Hence $25.85+15=40.85$, around $41 \%$ get information regarding agriculture with the help of mobile communication. 


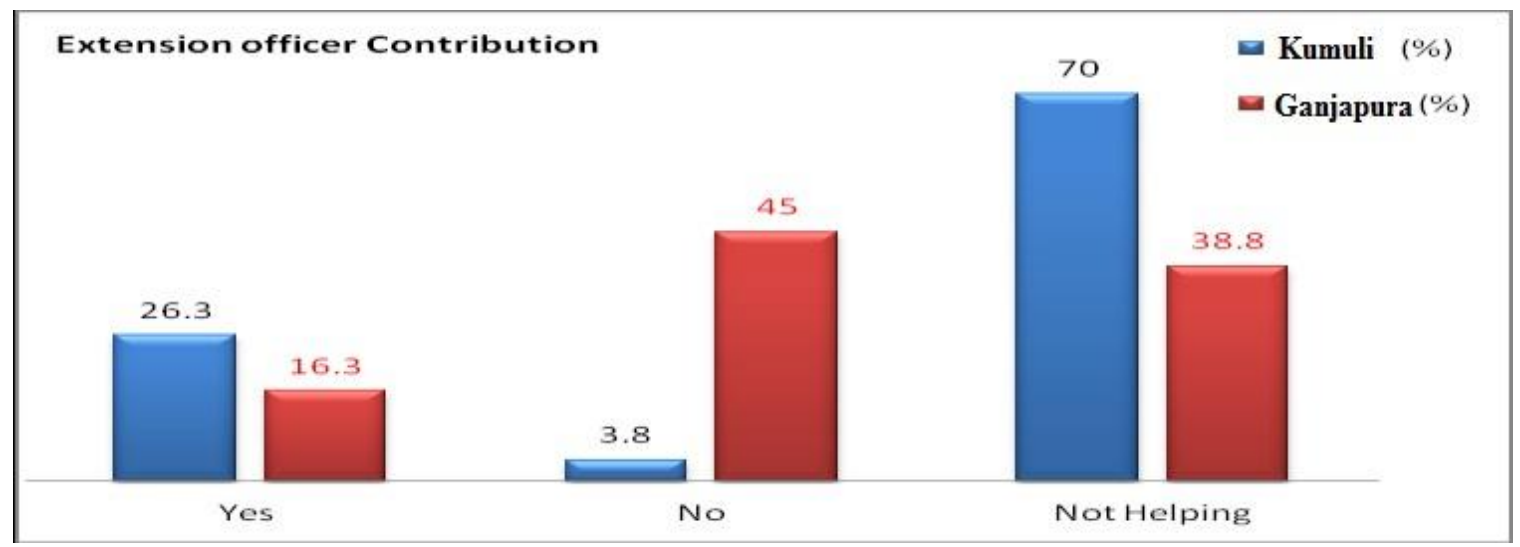

Graph No 8

Agriculture Extension officers are provides information directly to the farmers regarding new techniques and new way of cultivation. At initial stage extension officers are gain knowledge with the help of ICTs application after that information has disseminates to the entire farming community. As a result $21.3 \%$ famers increased their income with help of extension workers and ICTs applications.

\section{Findings and Conclusion:}

Media usage is higher among the farmers, nearly everyone $99 \%$ of them consumes on media, it's may be traditional or folk media, electronic media or new media. As per the data more or less farmers habits on multiple types of media. Among them around $11 \%$ farmers are using internet. An average 17\% of them access media for agro based knowledge, left percentage of them using for other purpose such as, entertainment, News, and other types of contents.

Among the media users, around 38\% know about the DD Kisan Channel. Those are know about the DD Kisan Channel $63.63 \%$ percent are watching the channel regularly, among them $97.5 \%$ said that all the content are relevant for agriculture extension.

Climate info play crucial role for the cultivation. Here at Raighar an average $12.50 \%$ of farmers' using ICTs application to know about climate/weather info. Some of them getting information from the ICTs, media, and by the observation. In Raighar basically farmers are learned cultivation techniques from the ancestors and friends. ICTs help them some extent to learn cultivation process. Basically information is transporting from extension offices or agriculture experts to the farmers, the percentage of Raighar is $53.8 \% .5 .7 \%$ are access through the ICTs applications.

New innovation techniques, use of modern technologies, high yielding seeds, usage of improve quality of fertilizers, pesticides management and other techniques-generally diffuse from one to more and again more to more. In Raighar $9.45 \%$ of farmers access all types of information through the help of ICTs application and also all those sources. At the initial stage extension officers, stake holders, and experts are gain trends through ICTs tools, in next stage they teach farmers through field visit, demonstration and workshop.

Mobile phone works as tools of ICT in Raighar block, an average $87.87 \%$ farmers using mobile phone. Among them $22.3 \%$ having smart phone when $77.7 \%$ having normal phone, tab user is zero. Mobile phone generally using here for communication with friends of relatives and the percentage is $36 \%$, and $23.29 \%$ using for communication and entertainment (Play game, listen music, watching video such types), an around $41 \%$ using for gather information regarding agriculture. Out of the mobile users $65 \%$ of mobile users never read messages which reach in inbox, but 35\% critically reading the messages. An average $38 \%$ of farmers receive messages from various portal, government offices or registered websites regarding farming needs. Internet users hike slowly in Raighar, lack of proper broadband connectivity, weak mobile network strength create barriers to access internet. In spite these $58.35 \%$ of farmers using internet, out of $22.3 \%$ smart phone users. Among the 58\% internet users, $62.50 \%$ farmers browse agriculture related content throughout internet. But only $3 \%$ of them regularly visits and know, farmers portals and such types of websites. 
Only $40 \%$ of farmers know about Kisan Call Centres, others are have no idea about it. Among the $40 \%$ users $23.49 \%$ keep contact in KCC, out of the $23.49 \%$ only $65.8 \%$ have registered their mobile no on KCC, in between $65.8 \%$ of registered farmers $75 \%$ get regular SMS from KCC. In Orissa's government free mobile distribution programmes for Kisan Credit card holders, nobody availed mobile phone in Raighar Block.

Laptop and PCs are rarely used in this region, only $1.75 \%$ of farmers have used such types of devices or progenies of farmers are using PCs laptops, they inform their parents regarding agriculture queries. 8.67\% of farmers are knows about the importance of ICTs application in Agriculture Extension. With the recommendations of extension workers, gathered information from ICTs application $21.3 \%$ of farmers increase their productions.

Due rural remote area there has no specials information dissemination centre or ICT help centre. Some people get information from the agriculture officers or Village Level Workers (VLW), Krisak Sathi, Village Agriculture Workers (VAW) and those regularly visit block agriculture office.

Mandi facilities very poor, only paddy are purchase by local mandi, perishable goods are sends to the neighbour state's mandi. About $8.7 \%$ farmers get benefit through the help of ICTs application or mobile phone. Mobile phone basically helps to gather information about market price; around 19\% of farmers learn market price output through the mobile phone.

ICTs application such as mobile phones helping farmers to changes the exiting attitudes. Through mobile phone farmers make interaction with market holders, kisan Call Centres, share information with friends, question answer with extension officers and browse internet on smart phone. Above all helps them to change the traditional pattern of cultivations.

\section{References}

[1] Gupta. O. (2006). “Encyclopaedia of Journalism and Mass Communication: Radio and Television. New Delhi: Isha Book Publisher.

[2] Sharma. D. (2004). Communication and IT Age. Mumbai: Himalayan Publishing House.

[3] Mohanty. L. \& Bohra. N. (2006). ICT Strategies for School A Guide For School Administration. NewDelhi: Sage Publication.

[4] Dasgupta. D., Choudhary. S., \& Mukhopadhyay. S. D. (2007). Development Communication in Rural Sector. Delhi: Abhijeet Publication.

[5] Bhatnagar. S \& Schware. R. (Ed). (2006). Information and communication technology in development. New Delhi: Sage Publication.

[6] Narula, U. (2011). Development Communication: Theory and Practice. New Delhi. Har-Anand Publication.

[7] Melkote. S. R. \& Steves. H. L (2001). Communication for Development in third World. New Delhi: Sage Publication.

[8] Green. L. (2001). Communication Technology and Society. London: Sage Publication

[9] Singhal. A. \& Rogers. E. M (2011). Indian Communication revolution: From Bullock Carts to Cyber Marts. New Delhi: Sage Publication.

[10] Hanson. J \& Narula. U. (2012). New Communication technologies in Developing Countries. Routledge, Publication New York.

[11] Ghosh. A. (2006). Communication Technology \& Human Development: Recent Experience in India Sector. New Delhi: Sage Publication.

[12] Koshore. D. \& Gupta. B. ICT for agriculture Development: A study in Indian Himalayan Region. The Electronic Journal of Information Systems in Developing Countries. Vol. 48.

[13] Kauffman. R.J. \& Kumar. K. (2008). Impact of Information and Communication Technologies on Country Development: Accounting for Area Interrelationships. International Journal of Electronic Commerce. Vol.13 